\title{
Organizational adaptation to climate change: learning to anticipate energy disruptions
}

\author{
Renato J. Orsato
}

Getulio Vargas Foundation (FGV), São Paulo School of Management, São Paulo, Brazil, and

Simone R. Barakat and José Guilherme F. de Campos School of Economics, Management and Accounting, University of São Paulo, São Paulo, Brazil

\section{Organizational adaptation to climate change}

\begin{abstract}
Purpose - This paper aims to investigate how organizational learning (OL) affects the development of anticipatory adaptation to climate change in companies. Because the need to learn increases in circumstances of greater uncertainty such as the case of climate change, one of the processes that can explain different levels of anticipatory adaptation to climate change (AACC) by companies is OL.

Design/methodology/approach - The research uses a case study design. Following the procedures of qualitative sampling, an exemplary case of organizational adaptation to climate change in a sector that is extremely affected by the impacts of weather events was chosen. Empirical data collection includes semistructured interviews and the collection of private and public documents. Such data were analyzed through thematic analysis.

Findings - The process of OL for anticipatory adaptation to climate change presents substantial differences from the traditional OL process presented by the specialized literature. In particular, the concepts of single- and double-loop learning were challenging to fit into the learning processes required for AACC.

Originality/value - Organizations have historically been working towards the adaption to external unforeseen events, but anticipatory adaptation to climate change presents new challenges and requires new forms of learning. Previous research has examined the interplay between learning and climate change adaptation, especially at the inter-organizational level. By developing research at the organizational level, this paper addresses a gap in the literature and shows that the required learning to adapt to climate change differs from the traditional learning, described in the management literature.
\end{abstract}

Keywords Climate change, Organizational learning, Anticipatory adaptation, Energy disruptions

Paper type Research paper

(C) Renato J. Orsato, Simone R. Barakat and José Guilherme F. de Campos. Published by Emerald Publishing Limited. This article is published under the Creative Commons Attribution (CC BY 4.0) licence. Anyone may reproduce, distribute, translate and create derivative works of this article (for both commercial and non-commercial purposes), subject to full attribution to the original publication and authors. The full terms of this licence may be seen at http://creativecommons.org/licences/by/4.0/ legalcode

The authors would like to thank the support received from the Center for Sustainability Studies of Getulio Vargas Foundation (GVces) and the access provided to data from Energias de Portugal (EDP), as well as the editors and two anonymous reviewers for their input and suggestions that resulted in a much-improved manuscript.

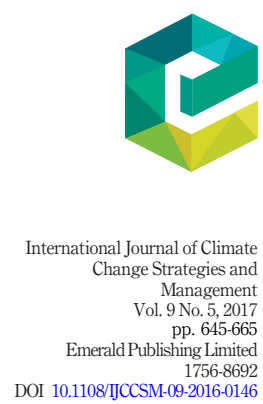




\section{IJCCSM 9,5}

\section{Introduction}

Weather-related disasters have historically posed significant challenges to organizations. Droughts, which occur for much longer periods than floods, hurricanes and tsunamis, to mention just a few, have all been part of natural cycles, which have impacted human organization. Global warming, in this respect, does not change the nature of natural disasters, but the escalation of intensity and likelihood of such events have major implications for organizations. By their turn, human organizations have also affected the natural environment, and today, few question the human meddling in significant changes in climate and weather conditions (IPCC, 2013). Nonetheless, despite the close interdependence between companies and the environment and the growing interest on corporate sustainability (Jabbour and Santos, 2008), the management literature has only recently dedicated attention to the pressing issues of climate change (Pesonen and Horn, 2014).

In practical terms, companies have also dedicated limited attention to climate change (Lupp et al., 2016). This is because, among other factors, management decisions are rarely based on their adaptability to the natural environment (Linnenluecke et al., 2013). At the extreme, some companies have even put efforts into denying climate change, let alone making efforts to adapt to it. Overtime, however, most realized that weather disruptions are likely to be more frequent and severe than before (Busch, 2011; Linnenluecke et al., 2012), and adaptation will eventually become a management imperative.

In general, adaptations related to environmental management take into consideration the organizational context and operational aspects, to deal with the complexity of environmental variables (Jabbour et al., 2010). Anticipatory adaptation to climate change (AACC)[1] is an outcome of interactions between endogenous and exogenous factors, which vary across organizations and industry sectors, and partly explains the different levels of preparedness to the effects of climate change (Berkout, 2012). For instance, the insurance and reinsurance industries have been in the forefront of anticipatory adaptation owing to the high financial impact that weather disruptions may cause to the industry, the healthcare sector, owing to the costs associated with the consequences of extreme temperatures and epidemics (Adger et al., 2005).

Indeed, some sectors are acutely vulnerable to climate change. In the electricity industry, for instance, peak electricity demand due to warmer and more frequent hot days could exceed the maximum capacity of transmission systems, as well as increase the risk of damage to facilities and infrastructure from extreme and unpredictable weather conditions (Center for Climate and Energy Solutions, 2008). However, the characteristics of the sector do not explain the differences in performance among organizations. Why some excel at addressing AACC while others lag? The literature review suggests that organizational learning (OL) is a potential explanation for differences in levels and pace of adaptation. According to Berkout et al. (2006), the process of OL has some theoretical proximity with AACC and, in empirical terms, it can also help organizations overcome barriers to adapt. Owing to its novelty, however, the specifics of OL for the case of anticipatory adaptation require further research (Linnenluecke et al., 2013).

Given this background, this paper investigates how OL affects the development of anticipatory adaptation to climate change. By answering the research question, this paper seeks to identify eventual differences between learning for AACC and traditional forms of OL. This was made possible through the development of a case study about a pioneer tool launched by a company operating in the electricity sector, in an area under the impacts of extreme weather events in south-east Brazil. The tool performs climate projections, providing information about possible disruptions in the distribution network caused by storms such as lightning and floods, which are expected to be more frequent and severe in 
the next decades. The paper is organized as follows: Section 2 discusses the concept of OL and its importance to organization adaptation to climate change, a relevant empirical concern. Section 3 describes the methods. Section 4 describes the case study and its results and Section 5 presents the discussion. Finally, Section 6 presents the conclusions.

\section{Organizational adaptation to climate change}

\section{Theoretical foundations}

\subsection{Organizational adaptation to climate change}

Organizational adaptation is a compromise between strategic choice and environmental determinism. "Adaptation is a dynamic process resulting from the relative strength and type of power or dependency between organization and environment" (Hrebiniak and Joyce, 1985, p. 347). In natural systems, human intervention may facilitate adjustment to expected climate and its effects. In human systems, adaptation seeks to moderate harm or exploit beneficial opportunities [Intergovernmental Panel on Climate Change (IPCC), 2013]. Therefore, what distinguishes adaptation to climate change from other organizational adaptation is the large-scale impact on companies' infrastructure, affecting production processes and distribution, as well as access to resource from its supply chain, either by systematic changes in the mean climate or by the increase in frequency and intensity in extreme weather events (Linnenluecke et al., 2013).

According to the specialized literature, there are three main types of organizational adaptation to climate change: utility-maximizing, behavioral and institutionalist. The utilitymaximizing approach is based on optimal choices between a set of clear alternatives whose costs and benefits are known and discounted over time. The behavioral approach relies on perceptions and capabilities by the organization, with the strategy chosen depending less on an objective assessment of costs and benefits and more on a messy process of sensemaking, learning and organizational adjustment. Finally, the institutionalist approach considers the adaptive capacity of an organization resting on perceptions and capabilities, as well as shaped and constrained by external social, cultural, political and economic structures and processes (Berkout, 2012). While there are several studies based on the institutionalist approach, there is a lack of research assessing costs and benefits of adaptation over time (utility-maximizing), as well as empirical investigations about decision-making and OL (behavioral) at the company level (Linnenluecke et al., 2013).

\subsection{Organizational learning and competence building}

The need for adaptation and improving efficiency normally explains the need for OL. To remain competitive and innovative, companies have to learn, aligning their activities, processes and strategies to changes in the environment. Hence, OL is not unique to climaterelated adaptations. Notions of OL emerged in the 1950s when behaviorists such as March, Simon and Cyert refuted the claim of economic models that organizational decision are uniquely determined by environmental constraints. They proposed firms as complex and adaptive systems that, owing to its internal complexity, are able to have substantial autonomy (Cyert and March, 1963). The concept of learning is dynamic and "emphasizes the continually changing nature of organizations" (Dodgson, 1993, p. 376). OL can be defined as "the capacity or processes within an organization to maintain or improve performance based on experience" (Nevis et al., 1995, p. 73).

Different types and levels of learning are also indicated by the specialized literature. For example, Argyris and Schon (1978) distinguished between single- and double-loop learning. In single-loop learning, organizations modify their actions according to the difference between expected and obtained outcomes. In double-loop learning, organizations are able to view and modify the values, assumptions and policies that led to the actions in the first 
IJCCSM

9,5

\section{8}

place. To make fundamental changes in basic assumptions about the competitive environment, the authors emphasized the need for double-loop learning to occur in organizations.

Regarding the process of OL, Huber (1991) proposes four constructs, widely accepted by literature (Tippins and Sohi, 2003):

(1) knowledge acquisition;

(2) information distribution;

(3) information interpretation; and

(4) organizational memory.

Knowledge acquisition is the process by which knowledge is obtained and consists of five sub-processes:

(1) drawing on knowledge available at the organization's birth;

(2) learning from experience;

(3) learning by observing other organizations;

(4) grafting components that possess knowledge needed by the organization; and

(5) searching for information about the organization's environment and performance (Huber, 1991).

Information distribution is the process of sharing information from different sources, leading to new information or understanding (Huber, 1991). For the learning process to be effective, information must be distributed to individuals who need it (Tippins and Sohi, 2003). Information interpretation is the process by which distributed information is given one or more commonly understood interpretations (Huber, 1991). As the consensus of meaning of the information evolves, global understanding of the information among company's members takes place and helps clarify how information may impact a company's future strategy (Tippins and Sohi, 2003). Finally, organizational memory means, as it suggests, storing knowledge for future use (Huber, 1991). Organizational memory is embedded in organizational members, tools and tasks and in networks formed by them (Argote and Ingram, 2000). These four constructs proposed by Huber (1991) have been empirically tested in later works (Jiménez-Jimenez et al., 2008; Pérez López et al., 2005; Sánchez et al., 2010). Hence, they have been proved as a trustworthy and consistent to measure OL.

For such a process to occur, it is possible to observe three (classical) conditions for OL (Levitt and March, 1988). First, behavior in an organization is based on routines that involve fitting procedures to circumstances. Second, organizational actions are history-dependent. Routines are based on interpretations of the past more than anticipations of the future, and organizations incrementally adapt to experience in feedback loops. Third, targets orient organizations. Their behavior depends on the relation between the outcomes they observe and the aspirations they have for those outcomes.

Figure 1 summarizes the processes involved in OL, by integrating the set of organizational actions required to learn, represented by the constructs proposes by Huber (1991), which are:

- knowledge acquisition;

- information distribution;

- information interpretation and organizational memory; and 


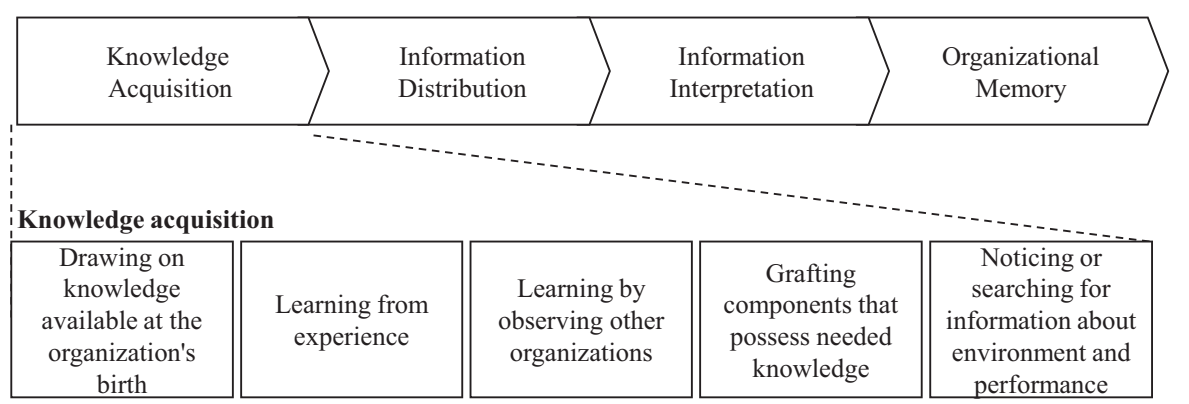

\section{Fitting procedures to circumstances}

Source: Adapted from Levitt and March (1988) and Huber (1991)
Organizational adaptation to climate change

Figure 1. Constructs in OL

- the classical observations of OL proposed by Levitt and March (1988), which consist in routines, history dependence and orientation to targets.

The ability to learn and adapt is critical to the performance and long-term success of organizations. The reason for some organizations to be better at learning than others is, therefore, a relevant research area (Argote and Miron-Spektor, 2011). Then, the investigation why some organizations are better at leaning in specific situations, such as the case of AACC, may reveal important and new elements to contribute the OL literature.

\subsection{Organizational learning for adaptation to climate change}

Learning is a process that enables companies to retain and improve competitiveness, productivity and innovativeness. In circumstances of greater uncertainty, such as the case of climate change, the need to learn increases (Dodgson, 1993). Despite the relevance, however, research on learning in the context of adaptation to changes in the natural environment is scant (Armitage et al., 2008). Such research gap is partly explained by the lack of empirical evidence, with only a scarce group of organizations developing strategies and practices deliberately targeting climate change. Although organizations have developed great adaptive capabilities, most still lack the skills and resources to couple with the disruptions brought by extreme weather events (Linnenluecke et al., 2012).

For AACC to occur more often, companies need to acquire specific and non-traditional knowledge on natural sciences and ecology for three reasons. First, the unpredictable and long-term consequences are hard to anticipate. Even the climate models are not well-suited for decision-making and carry a significant degree of uncertainty. Second, specific knowledge about these uncertainties is difficult to assess because it is subjected to chaos and complexity. Not only variables related to the natural environment but also intervenient variables such as the level of greenhouse gas emissions may affect the climate in the future. (Busch, 2011; Hallegatte, 2009). Therefore, interaction with scientists can facilitate the acquisition of knowledge about this issue. They can help organizations to understand the problem, provide data, find better solutions and mobilize and train practitioners to 
IJCCSM

9,5

650

operationalize, monitor and evaluate complex situations in which vulnerabilities regarding the natural environment may emerge (Vogel et al., 2007).

Overall, preventing the consequences of global climate change is very difficult for companies. Even the best organizational climate change adaptation system is not capable of fully anticipating and dealing with unanticipated disruptions. Facing such challenge requires a systemic and dynamic capability to rapidly adapt to the non-foresighted disruptions, which means, formidable ability to learn. Such requirements can best be seen through an empirical example. Singular examples of learning practices of approaching adaptation to climate change can reveal to what extent learning is used in concrete working practice at the stage of implementation and decision-making (Storbjörk, 2010).

\section{Methods}

This study investigates the following research question:

$R Q 1$. How does organizational learning affect the development of companies' adaptation to climate change?

This question was addressed by developing a case study, which can be used mainly to promote an insight about a subject or to redefine a generalization. The single case study is an opportunity to learn about a phenomenon and to reach theoretical generalization (Stake, 1998). Single case studies can help change our views about organizations and tell good stories that have a theoretical sense (Dyer and Wilkins, 1991). Additionally, Siggelkow (2007, p. 21) emphasizes that case-based research "can also help sharpen existing theory by pointing to gaps and beginning to fill them". This study searched for peculiar aspects of OL for AACC. Hence, identifying leading-edge organizations, i.e., that are ahead of their counterparts, was needed to generate comprehensive theory (Dubey et al., 2017). Also, as OL occurs over time, case study is the most appropriate research method to grasp such a phenomenon, which justifies it to be a preferable method used for the study of OL (Argote and Miron-Spektor, 2011). By in-depth evaluation of such peculiar aspects in a qualitative approach, this study contributes to the development of a specialized literature about AACC, as well as to organization and management studies.

\subsection{Case selection}

Achieving a rich understanding of the phenomenon under investigation depends on the adequate choice of a case (Stake, 1998). In this study, the suitable company should:

- operate in a sector highly vulnerable to climate change; and

- have implemented a successful case of adaptation to climate change.

As a result, the electricity distribution (sub) sector was chosen. In this industry, companies are likely to be more vulnerable to climate change because they rely on long-lived and exposed capital assets and are dependent on climate-sensitive inputs or locations (Linnenluecke et al., 2012). The selected company was EDP Bandeirante, a subsidiary of the Portuguese EDP (Energy of Portugal), which has implemented a successful tool that uses climate variables to predict the impacts of climate on the company's electric grid. The socalled ClimaGrid project enables EDP Bandeirante (henceforth, EDP for short) to quickly respond to weather-related disruptions.

The choice of ClimaGrid was based on two main premises: that knowledge can be embedded in tools (Argote and Ingram, 2000) and research about the development of tools has the potential to clarify the process of knowledge creation for OL. Additionally, the 
Brazilian electricity sector is exemplar in demonstrating both the challenges faced with climate change disruptions and the empirical relevance of research capable of uncovering how organizations learn to anticipate.

\section{Organizational adaptation to climate change}

\subsection{Data collection and analysis}

A set of data sources grounded the case, assuring the process of triangulation and improving the validity (Voss et al., 2002). This research used a semi-structured script built on the main constructs of OL processes (Appendix) to conduct in-depth interviews. The purpose of the questionnaire was to examine the aspects of each construct of OL proposed by the literature (Figure 1) to verify how this process contributed to the AACC and whether differences could be found between leaning for AACC and other types of learning, required by companies.

The interviews were conducted with six managers from different areas of the company: R\&D, EDP institute, sustainability, operations and customer service (call center); energy risk and planning; and meteorology. The interviews, developed in the period of June to November 2014, were recorded and transcribed, resulting in a total of $346 \mathrm{~min}$. Excerpts from the interviews with the manager and meteorologist from energy risk and planning department, all interviews were face-to-face and occurred at the company headquarter and at the operations center, where the use of tools by employees was also observed. All the information from the interviews is displayed in Table I.

Finally, to complete and triangulate, the scientist from the INPE (National Institute of Space Research), who developed and had the responsibility for the project inside the research institute, was consulted. The scientist answered 11 questions by email. The number of interviews and the amount of data collected were determined by the decision of how and for how long the complexities of the case should be studied, as not everything about a case can be understood (Stake, 1998). Public data and internal corporate documents,

\begin{tabular}{|c|c|c|c|c|}
\hline $\begin{array}{l}\text { Interviewee } \\
\text { identifier }\end{array}$ & Job title & $\begin{array}{l}\text { Years in } \\
\text { company }\end{array}$ & Involvement with ClimaGrid & $\begin{array}{l}\text { Interview } \\
\text { duration } \\
\text { (Minutes) }\end{array}$ \\
\hline I.1 & R\&D manager & $\begin{array}{l}\text { Since } 2007 \\
\text { (7 years) }\end{array}$ & $\begin{array}{l}\text { Follow-up and management of } \\
\text { ClimaGrid development }\end{array}$ & 104 \\
\hline $\mathrm{I} .2$ & $\begin{array}{l}\text { Director of EDP Institute and } \\
\text { former sustainability manager }\end{array}$ & $\begin{array}{l}\text { Since } 2005 \\
\text { (9 years) }\end{array}$ & $\begin{array}{l}\text { Experience in promoting the } \\
\text { Climate Change agenda within EDP }\end{array}$ & 40 \\
\hline I.3 & $\begin{array}{l}\text { Customer Service manager } \\
\text { and former operations } \\
\text { manager }\end{array}$ & $\begin{array}{l}\text { Since } 2011 \\
\text { (3 years) }\end{array}$ & $\begin{array}{l}\text { Heavy user of ClimaGrid and giving } \\
\text { feedback for the improvement }\end{array}$ & 85 \\
\hline I. 4 & $\begin{array}{l}\text { Sustainability and innovation } \\
\text { manager }\end{array}$ & $\begin{array}{l}\text { Since } 2011 \\
\text { (3 years) }\end{array}$ & $\begin{array}{l}\text { Experience in promoting the } \\
\text { Climate Change agenda within EDP } \\
\text { and interface between sustainability } \\
\text { and innovation }\end{array}$ & 64 \\
\hline I.5 & $\begin{array}{l}\text { Manager of energy planning } \\
\text { and risk }\end{array}$ & $\begin{array}{l}\text { Since } 2011 \\
\text { (3 years) }\end{array}$ & $\begin{array}{l}\text { Experience in measuring and } \\
\text { analyzing the effects of climate }\end{array}$ & $53^{\mathrm{a}}$ \\
\hline I.6 & $\begin{array}{l}\text { Meteorologist of energy } \\
\text { planning and risk }{ }^{\mathrm{a}}\end{array}$ & $\begin{array}{l}\text { Since } 2012 \\
\text { (2 years) }\end{array}$ & $\begin{array}{l}\text { variables within company's } \\
\text { operations }\end{array}$ & \\
\hline
\end{tabular}

Note: ${ }^{\text {DDyadic interviews }}$

Table I.

Source: Authors

Interviews conducted 


\section{IJCCSM 9,5}

including reports and press releases of both the project and the company as a whole, were also gathered.

For data analysis, first, all the interviews and documental data were coded manually according to the constructs of OL processes, i.e. information were organized into meaningful categories and labeled. Then, it generated meaning by interpretation of data beyond their categories, exploring the way by which the emerging themes are interconnected and connected to the existing literature (Ruona, 2005).

\subsection{Objects of analysis for case development}

The case development focused on EDP (Energy of Portugal), an energy distributor operating in southeastern Brazil, where the software ClimaGrid was developed. The following sessions provide the basic information of both the company and the tool.

3.3.1 The company: EDP. EDP was publicly incorporated in 1976 but later became a limited company as a result of the nationalization and merger of Portuguese companies in the electricity sector. Currently, EDP operates in 13 countries, with more than 9.6 million customers and 12,000 employees. In Brazil, EDP operates in nine states, in activities ranging from hydro, thermal and wind generation and distribution of electricity. EDP Bandeirante is a subsidiary in Brazil which distributes energy for 1.7 million customers in 28 municipalities in the state of São Paulo, in an area of $9,600 \mathrm{~km}^{2}$, through its almost $28,000 \mathrm{~km}$ of aerial cabling and $158 \mathrm{~km}$ of underground cabling distribution.

The current network of the electricity industry in Brazil emerged from the crisis and consequent rationing of electricity in the early 2000s. In 2003, the federal government, which had been debating alternatives for the Brazilian Electricity Model, along with industry, academic and research specialists, started to implement a new model (Tankha, 2008). The wholesale electricity supply was divided into old markets, designed to cover power plants constructed before 2004, and new markets, created with the aim of spurring new investments via long-term supply contracts (Bajay, 2006; Tankha, 2008). The generation segment is highly pulverized, with a mix of prices regulated or freely negotiated. Transmission and distribution are natural monopolies, as the infrastructure requires centralized planning and sharing among the generators, and its prices are heavily regulated. The commercialization segment is recent, emerged as a liberalization tool, resulting in more flexible price mechanisms in the retail market.

The comparative advantage of the Brazilian electric sector (abundant land, water, sun and wind) makes it particularly vulnerable to the extreme weather events caused by global warming. The hydropower system relies on extensive reservoirs based on a multi-annual regularization system, and hydropower plants located in rivers basins that are usually distant from the main consumers' centers and therefore require long transmission lines (Pereira et al., 2013).

The Brazilian electricity power system has been designed for a relatively stable climate, certainly not considering the effects of global warming. According to the Brazilian National Institute for Space Research (INPE, 2010), 99 per cent of the Brazilian electricity distribution networks are aerial (cables supported by posts) and thus completely exposed to weather conditions. Brazil is a country with the highest incidence of thunderstorms in the world, with about 60 million discharges per year.

Despite the risks, the Brazilian electricity sector has never paid due attention to the threats of climate change (Lucena et al., 2010). Only recently the government and companies working in the sector started addressing the issue of adaptation to climate change. Only a few firms are working on the issue and even less firms, such EDP, are excelling - the rational for choice of our case study. 
The area in which EDP operates in Sao Paulo is the most affected by discharges. One-third of the 15 municipalities most affected by lightning in the state of São Paulo are under the concession (by the government) area of EDP. In this respect, EDP materialized its efforts to adapt to climate change by developing ClimaGrid, a tool that performs climate projections, providing information about possible disruptions in the distribution network.

3.3.2 The tool: ClimaGrid. EDP, in partnership with the INPE, launched the ClimaGrid tool on December of 2010. ClimaGrid uses innovative technology based in the "intelligent" grid concept. The tool consists of an integrated platform of climate and electrical data and a

Organizational adaptation to climate change set of computational analysis systems. It combines environmental, meteorological data (parameters such as wind speed and direction, air temperature, air humidity, rainfall levels and atmospheric pressure) and information about electrical system occurrences to assess the degree of exposure of EDP's distribution lines to disruptions caused by climatic variables, mainly electrical discharges. Thus, using ClimaGrid, EDP may predict, with a high degree of accuracy, possible disruptions in the system with $24 \mathrm{~h}$ of antecedence, allowing maintenance procedures to be carried out more quickly and efficiently. The platform was the first of its kind to address this issue in Brazil, and one of the first in the world (INPE, 2014). Adopting technologies and using climatic information are important assets for building specific capacity to adapt to climate change (Eakin et al., 2014).

The ClimaGrid tool is exemplar of the learning process required to develop organizational adaptive capabilities, as it allows EDP to be prepared for possible disruptions caused by storms, such as lightning and floods. The company tries to anticipate the effects of climate change to minimize them, leading to a better utilization of electrical energy [Sustainability Center of Getúlio Vargas Foundation (GVces), 2013]. This is because one of the predictions of climate change is higher incidence of lightning and more severe storms, which will lead to a greater impact on the distribution network, especially in Brazil, where the distribution network is aerial and, thus, very susceptible to weather.

The computer software integrates a wide range of weather and environmental variables, characterizing a smartgrid for the management of electricity networks (EDP, 2013a). For instance, it allows the company to identify the exact location, size, speed and direction of cloud displacement, which is one of the items of great interest of ClimaGrid (EDP, 2013b). The anticipated knowledge of the evolution of storms allows the company to optimize the management of maintenance teams, directing them to the most likely sites of occurrence, improving prevention and decreasing the response time of possible shutdowns. This platform has contributed to significant improvements in service quality with reduction in frequency and duration of supply disruptions (EDP, 2013b).

\section{Results}

Learning is a dynamic process and emphasizes the continually changing nature of organizations, as shown in Section 2.2. This section presents and discuss the learning process embedded in the ClimaGrid case, to explain the relationships and logic between the constructs of OL and, more broadly, how OL contributes to AACC.

\subsection{Knowledge acquisition}

As Figure 1 depicts, knowledge acquisition is the process by which knowledge is obtained, and it consists of five processes:

(1) drawing on knowledge available at the organization's birth;

(2) learning from experiences;

(3) learning by observing other organizations; 

IJCCSM
9,5
(4) grafting components that possess knowledge needed by the organization; and

(5) searching for information about the organization's environment and performance.

4.1.1 Drawing on knowledge available at the project's birth. Because our analysis focuses on the process of OL embedded in a specific tool, it was considered the knowledge available at the organization on the project's birth. Similar to previous studies that have shown that climate adaptation is largely dependent on the interaction between different actors so as to encourage learning (Storbjörk, 2010), ClimaGrid emerged from the interaction between the company and a research institute (INPE), motivated by a public actor, the National Agency of Electricity Energy (ANEEL[2]), which demands the investment of 0.2 per cent from distribution companies' net operating revenue in R\&D projects. Considering that the downscaling of climate models tends to be expensive and technically complex, allowing only a few institutions to use it (Ziervogel et al., 2008), the partnership with INPE was central to assure the availability of the computational capacity to store and process data on climate, one of the ClimaGrid's cornerstones.

4.1.2 Learning from experience. Early in the project, the tool was restricted to monitor and understand the effects of lightning, such as the magnitude and impact in the distribution network. As the project evolved, the lightings were crossed with EDP's geolocalization systems, to determine the region they fall in and, consequently, correlate the effect between the lightning and the shutdown of the network. By inserting the information about lightning into the company's technical information system (TIS), the impact on the shutdowns of the distribution network became evident. However, because the system cannot rely solely on the extrapolation of past patterns, as historical patterns will not necessarily repeat in the future, there is a major barrier to learn from experience in issues related to climate change.

Even though the usefulness of ClimaGrid was evident for the team who led the project, staff in the frontline of operations could not clearly see its value until 2012. In that year, a fierce wind in the downtown of a city under the EDP concession was turned into chaos. After overcoming the crisis, data showed that, had ClimaGrid been fully implanted, the anticipatory capacity for adaptation could have been much higher. Therefore, the occurrence of an extreme weather event was essential to legitimize the use of ClimaGrid inside the organization. This is because personal experiences provoke higher impact and stronger motivation in people in charge than statistical information (Marx et al., 2007).

4.1.3 Learning by observing other organizations. EDP tracks several initiatives regarding climate change adaptation through its $R \& D$ department. To learn and exchange knowledge, employees attend national and international academic and practitioners' events. Cooperation projects with other companies from the Brazilian electricity sector are also in the agenda. However, EDP faces a challenge in exchanging knowledge with other companies. First, the Brazilian electricity companies are not innovative in research on climate change adaptation. Second, technologies developed abroad rarely fit the Brazilian climatic reality. Finally, there are serious limitations to acquire and exchange knowledge in this domain, as few companies are disclosing something. In sum, as adaptation tends to be conducted in a local/regional spatial scale, the local context should facilitate the exchange of knowledge with other organizations (Füssel and Klein, 2006). However, besides EDP there was no other company operating in the same region, substantially restricting the chances of EDP acquiring knowledge from observing other organizations.

4.1.4 Grafting components that possess needed knowledge. Comprehending and learning to manage climate variables is not a simple task. Because the weather may alter suddenly, anticipating the behavior of climate variables on a daily basis remains a major challenge. 
Rather than planning for the medium or long term, it is necessary to perceive and rapidly adapt to disruptions in the distribution system on a daily basis.

Because climate forecast demands both extensive technical and specific knowledge, EDP has gathered support and partnership from INPE to develop and implement ClimaGrid. The partnership includes the forecasting statistical model, the software and its interface, the updated daily climate database with information from all over the world and training of EDP's engineers on how to extract and interpret climate information. Hence, the partnership was crucial for EDP. The uncertainty of the project was too high to rely on internal staff.

4.1.5 Searching for information about the organization's environment and performance. As soon as the majority of EDP personnel realized that ClimaGrid could substantially increase the operations efficiency, the tool gained widespread support. After 2010, ClimaGrid became an encompassing climate monitoring system, tracking cloud-ground lightning, cloud-cloud lightning, wind, rainfall and temperature and humidity. After developing successive R\&D projects, in 2011, EDP started using ClimaGrid more broadly, for better operational decision-making. ClimaGrid success has been experienced on a daily basis, predicting climate events with about 90 per cent accuracy. The tool has been fully integrated into the company IT platform, and there are plans to extend the time of forecasts from current $24 \mathrm{~h}$ to $72 \mathrm{~h}$.

However, measuring the effects of ClimaGrid on quality (indicators) has proven difficult. Energy distribution companies in Brazil have their services evaluated by two overarching quality indicators: duration of interruption and frequency of interruption per consumer. Despite the efforts, EDP has not been able to isolate the effects of ClimaGrid on such indicators, as measurers such as the implementation of compact distribution networks and live-line working (i.e. working with the system energized) also affect quality indicators. Despite such challenges, within the company, there is a consensus that the major cause of interruptions is weather-related. The worsening weather conditions and the increasing quality requirements from regulatory agencies transform the link between ClimaGrid and the company performance into a strategic issue. The tool is expected to play an increasingly important role in supporting decision-making to meet the required standards, allowing EDP to be positioned as the market leader (EDP, 2013b).

\subsection{Information distribution}

Information distribution is the process of sharing information from different sources, leading to new information or understanding, as described in Section 2.2. The information provided by ClimaGrid is interpreted and distributed by the engineers from the operations center, who are trained by INPE. These engineers prepare a daily report with information about climate previsions that is distributed throughout the company.

The operations center is the main user of the data provided by ClimaGrid, but other departments also use the information, such as the call center, customer relationship agencies, among others. These areas ask for useful information. For example, while EDP operations team is fixing a specific problem in a given geographical area, it is possible to pre-alert the call center about an expected increase on the number of customers' complaints on electricity breakdowns, and ask them to provide assurance by giving precise information about the causes of the breakdowns. Even the media can be alerted so as to pass the information to local inhabitants.

Previous studies analyzing the effect of communication as moderator of the level of individual engagement, regarding climate change, can help understanding the process of information distribution (Morton et al., 2011). Such studies show that the way the message is framed influences responsiveness. Messages of risk avoidance tend to have a positive effect on 
$\operatorname{IJCCSM}$
9,5

656

individual behavior. So, communicating possible, effective and not-too-costly options to adapt to climate change (Grothmann and Patt, 2005) is important to shape the perceived adaptive capacity. Therefore, ClimaGrid may have been welcomed because it provides information that allows the company to minimize losses. Because the knowledge about previsions of climate variables and past weather events is recorded by the tool, such information can be easily distributed across the company. The understanding of such information, however, is another matter, discussed next.

\subsection{Information interpretation}

Information interpretation is the process by which distributed information is given one or more commonly understood interpretations. Information on climate gathered by ClimaGrid might be used in three main ways:

(1) gradually improve ClimaGrid's forecasting model;

(2) anticipate disruptions; and

(3) find solutions for recurrent problems.

Gradually extending the information database about the geographical climate variables helps improving the statistical model behind ClimaGrid. In terms of anticipation, the system can be used to improve the readiness the operational teams to act in areas where the distribution lines are likely to suffer breakdowns. For this planning to work on a daily basis, EDP engineers gather the information processed overnight by ClimaGrid from INPE's database and make a short and objective written report, indicating the daily expected climate behavior. To assure a common understanding across the organization, the interpretation of climate variables is somewhat centralized. On the other hand, the deployment of the applied information is specific to each organizational branch.

Following the same logic of the information distribution, the tool facilitates consensus about the meaning of the information, as they are previously interpreted by the engineers trained by INPE. The interaction between INPE and EDP staff through ClimaGrid was critical to turn "climate knowledge" into "usable science" (Dilling and Lemos, 2011). Indeed, ClimaGrid eases decision-making by giving a more objective output to EDP from a huge source of data processed by a complex set of scientific and statistical models. As Moss (2007) poses, information derived from discovery-driven basic research is essentially different from information derived from "science for decision making", which requires less uncertainties and shorter-term application. Besides, building trust in situations bridging science to practice comes slowly and usually just after an initial process of tension between scientists in charge of providing information and practitioners in charge of decision-making (Vogel et al., 2007).

Even though some areas within EDP are constantly making use of the information provided by ClimaGrid, they are not necessarily aware of climate change issues. The overall understanding of the meaning of the information provided by ClimaGrid among company employees is still restricted. This evidence reveals that the learning process of AACC in the company is still characterized by single-loop learning, which relates to improvements in existing organizational processes. These improvements are hard to be identified, as expected outcomes related to climate change are intricate to define, owing to complex and intertwined interactions among climate variables. On the other hand, learning embedded in the tool is already promoting changes in values, assumptions and policies related to climate change issues, which characterize the double-loop learning. For double-loop learning to effectively happen, fundamental changes in basic values, 
assumptions and policies related to AACC would be required, which is a subject still far from the practical concerns of most managers and employees.

\subsection{Organizational memory}

Organizational memory refers to storing knowledge for future use. In this respect, at the time of our research the company did not have formal procedures for the use and interpretation of data. Only three engineers were capable of interpreting data provided by INPE rendering EDP reliant on external parties. These engineers forecast, interpret the data and disseminate the results throughout the company, suggesting the limitations of this final stage of OL. Nonetheless, all climate data, such as winds, rainfall, temperature and humidity, are stored for future use. Through the use of this information, it is possible to better manage the network planning and operation.

The historical information on climate might be recovered through ClimaGrid to be used in foreseen and unforeseen situations. For example, it is common for customers to complain about damages in domestic electronic devices, caused by electricity breakdowns. For EDP, it is difficult to assess whether the damages were provoked by electricity breakdowns or other causes. With the complete map, including the exact location where the lightning fell, it will be easier for customer relationship department to decide whether EDP is accountable for customers' losses. Other departments may also benefit. For instance, the quality department might link the ClimaGrid with quality performance indicators, and the engineering department might use this information to better understand the causes of flaws and burnout in EDP's transformers.

The use of stored information might also be used in issues not directly related to climate change. For example, the implementation of new regulations allowing the inclusion of renewable sources in distribution networks, requires exactly the kind of data memorized via ClimaGrid. Such potential usefulness of climate information demonstrates the unforeseen benefits of an effective OL process (Templeton et al., 2002).

\section{Discussion}

The development of the case study generated insights about OL in the context of AACC. The case uncovered clear differences between the process of OL for ZACC and "traditional" types of OL mentioned by the specialized literature. Table II presents some of the associations between the specialized literature and the results of our research.

By confronting the specialized literature with outcomes of the case study, a framework that integrates the particularities of AACC with the constructs of OL is proposed below. The framework, depicted in Figure 2, has some underlying assumptions. First, it considers organizations not only aware of the need to adapt but also willing to take actions. Second, the framework focuses on adaptation to extreme weather events and not to consistent and lasting changes in the climate variables, whose learning process is likely to be rather different.

In the framework, the process of learning initiates with the acquisition of knowledge from a multiple set of sources, as described by the boxes a, b, c, $d$ and e. The large volume of data also carries a high level of uncertainty, characteristic of the issues related to AACC. Thus, data might be selected considering the lower degree of uncertainty (see Item 1 in the figure). Then, to transform data into information for distribution, it must be: f) synthetized; $\mathrm{g}$ ) focused on specific situations; and h) user-friendly. The amount of data in this moment is still substantial and has to be interpreted by individuals with knowledge on the climate variables, which also are responsible to provide assurance of the distribution of feasible knowledge for decision-making. The distributed information might be used in decisionmaking of new actions and programs or to improve the ongoing ones (Item 2), which will be 


\section{IJCCSM \\ 9,5}

\section{8}

Knowledge acquisition

Drwing on knowledge available at the project's birth

Learning from experience

Learning by observing other organizations

Grafting components that possess needed knowledge

Searching for information about the organization's environment and performance
Exemplary quotes

"The company always has projects in partnership with universities, research centers and manufacturers. In the case of ClimaGrid, we went straight to INPE, which is a research institution. In the case of a previous project, we developed a smart meter, so it was made in partnership with an equipment manufacturer" (I.1)

"If you get the historical rainfall and stream flow and elaborate statistical models to predict the rainfall tomorrow, you'll miss it. Historically, it rains more in January but this year did not rain. So, history not necessarily predicts what will happen. The weather is very crazy nowadays" (I.1)

"We share the results of the ClimaGrid project in national and international events and, in these events, we meet people who like the project, work with similar things and come to discuss with us. So we end up learning, having ideas and improving"(I.1)

"We look at the market and we follow what other companies are doing, but this is so new that I think that few companies disclose something ... We also try to talk to our colleagues in Portugal but the reality there is very different. So, for example, right now they are going through periods of flooding, while we're facing droughts" (I.4)

“As far as I know, companies like EDP can't afford to keep specialists in a given subject. It is not feasible. ... And, as far as I know, there is no professional dedicated to climate change issues ... It won't be and I doubt it would make sense anyway" (I.2)

"The search for learning is historical. We look at our results, based on quality indicators. We have the DEC indicator, which is related to duration of interruptions and the FEC, which is the frequency of interruptions. We analyze them through the causes and found that the major cause is weather-related" (I.3)

"We are unable to measure the effect of ClimaGrid on the reduction of the interruption duration, because there are also many other actions made by the company, as compact network, live line work etc. ... But, of course, there was a positive impact" (I.1)

"Today we generate daily forecast reports [on the expected behavior of climatic variables] for the concession area .... Those reports are dispatched to all the network operational teams. Also the Operation Center Coordinator plan how they will deploy the operational teams [when interruptions in the energy distribution caused by climatic variables are expected]" (I.1) "This daily report [summarized weather information, prepared by the engineering team] goes to the entire company. So, which department of the company is able to do this reading and send it to the whole company today? It's the Operations Center. It is the most affected area The
Table II.

Data matrix: Organizational learning for $\mathrm{AACC}$ 


OL construct OL sub construct $\quad$ Exemplary quotes

Customer Service receives, the commercial offices receive, the Operational teams receive, and the Engineering receives. These are the main areas. ... you may imagine whether the person [from those areas] should have to do the reading [of the raw data on weather]. We would spend unnecessary energy" (I.3)

Information interpretation

Organizational memory
"I think they [referring to the Operational teams] can link the tool to the climate, especially because the name of the platform makes them think about it, but I do not know to what extent they see the global challenge of climate change. I know this is a matter of acculturation and awareness. Perhaps we have not reached that point with them. I guess they do not see it as contributing to the management of climate change" (I.4)

"There is always a little change in the way people think. Once you develop a tool that generates results, improves quality indicators and routines, I think people begin to think differently. Not only senior management, but even others begin to think differently on their daily life" (I.1)

"The data stored in ClimaGrid might help to better understand the potential to incorporate distributed energy into the grid, mainly based on wind, sun and rain. On the demand side, ClimaGrid will also allow the study of rainfall, temperature and humidity, which influences electricity consumption" (EDP, 2013b)

interpreted through i) interactions between scientists/technicians and decision-makers and j) the translation of climate knowledge for business language. Finally, organizational memory occurs simultaneously with three other phases and (Item 3) generates feedback of needed resources and information to improve or to keep the adaptive capacity. Decision-making may also benefit by using the data and information stored into the organizational memory in many unforeseen ways. For the information on climate, mainly, it requires massive storing and processing capacity. In the information distribution phase, processed data on climate are used, which are accessed through a user-friendly platform.

\section{Conclusion}

The level of anticipatory adaptation to climate change (AACC) developed by a company depends on industry circumstances and internal competences. Because the need to learn increases in circumstances of greater uncertainty, such as the case of climate change, one of the processes that can explain different levels of AACC by companies is OL. For this reason, this paper investigated how OL affects the development of companies' adaptation to climate change. Previous research has examined the interplay between learning and climate change adaptation (Armitage et al., 2008; Baird et al., 2014; Owens, 2010), but not at the organizational level, considering learning as a process. Indeed, by analyzing over 2,400 papers published under the topic of climatic change, Arnell (2010) identified a shortage of case studies about such process. This explains the methodological choice of the research. 


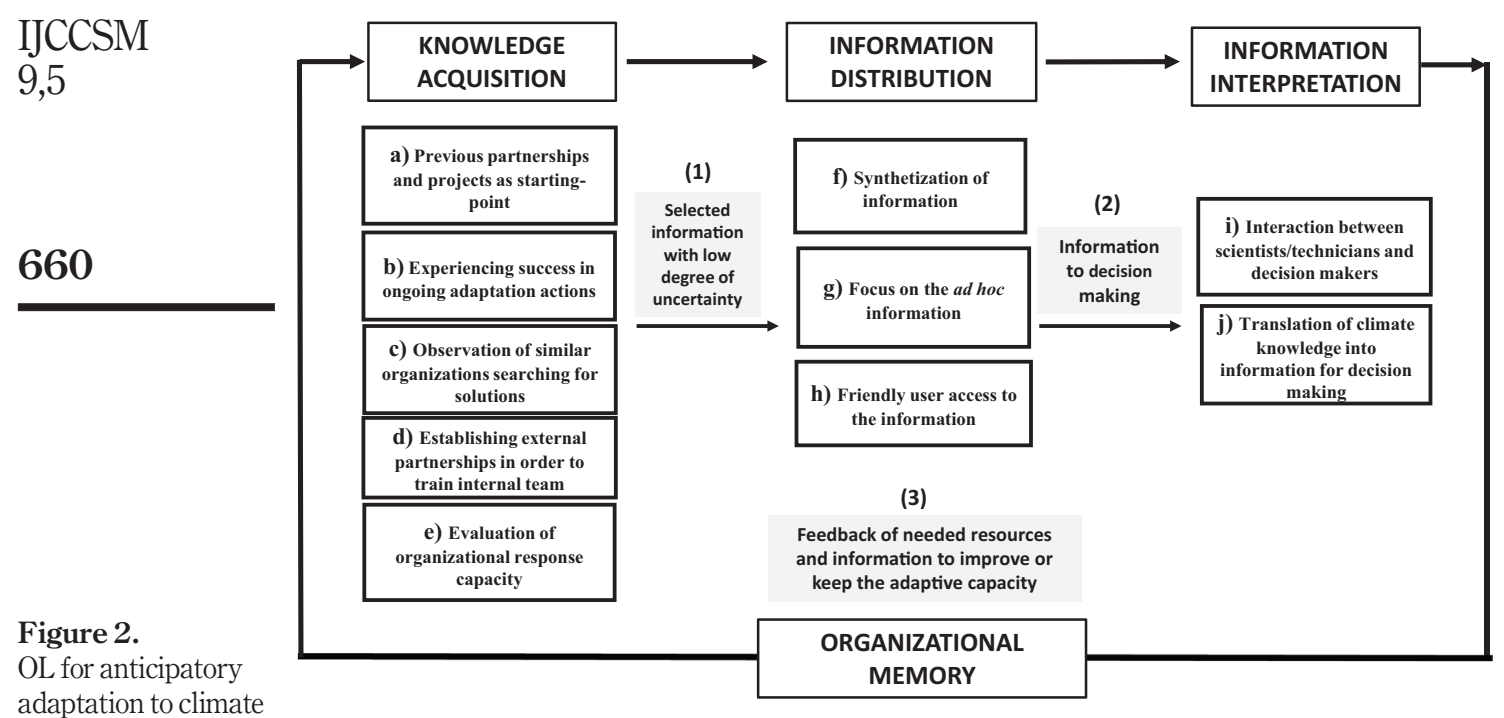

Source: Authors

Owing to the increase in frequency and intensity of climate-related disruptions faced by the Brazilian energy distribution, this paper addressed a case of exemplary climate adaptation developed by a company operating in this sector.

The results showed clear differences between OL for AACC and other types of adaptations usually made by organizations. The classical observations of OL presented by the specialized literature were not found in our research for three main reasons: first, there is no routine of organizational behavior that can be used as the basis. Routines for organizational adaptation are based mainly on future anticipations, rather than on past experiences. Second, organizational knowledge required to change rapidly is simply not available. Improving performance based on experience is limited because severe climatic disruptions do not follow patterns of behavior and many have not even occurred. Third, learning by observing other organizations can also be very restrictive, as the information necessary to deal with climate change issues is largely unknown.

The concepts of single- and double-loop learning are also challenging to fit into the learning processes required for AACC. In single-loop learning, expected outcomes are extremely hard to define owing to the complex interactions among climate variables and may bring highly unpredictable consequences, Nevertheless, our study has shown that experiencing success in the short term generates a positive feedback to follow-up in the adaptation plan. Regarding the double-loop learning, AACC is still far from the practical concerns of most managers, who are still concerned with climate change mitigation, rather than adaptation, hindering fundamental changes in basic values, assumptions and policies related to AACC.

Learning within organizational boundaries alone might be insufficient. The interaction with other organizations searching for adaptation solutions would ease the process of acquiring knowledge. As the ClimaGrid case showed, the knowledge needed for anticipatory adaptation can be more rapidly and less costly acquired via partnerships with specialized organizations, such as research institutes. Indeed, the case revealed that learning for AACC requires learning across multiple organizations, including government and other businesses. 
The interaction between multiple actors and organizations has the potential to generate problem-oriented knowledge, which may have practical applications. Such outcomes suggest that further research on how social learning occurs among different actors would be insightful for theory building. On the empirical side, bridging the gap between scientific climate knowledge and climate information for decision-making requires time and interaction between technicians/scientists and users of information.

The study also revealed important insights for both theorization and practice regarding information processing. Organizations process climate risks more easily and effectively when:

- the degree of uncertainty is low;

- the occurrence is imminent; and

- there is a potential use to decision-making to reduce the likelihood of losses.

Such outcomes suggest that bridging the gap between scientific climate knowledge and climate information for both decision-makers in private organizations and policy-makers working in the public sector requires time and intense interaction between technicians/ scientists and users of information.

Owing to methodological limitations, such findings have to be seen with caution. Single case studies use an inductive approach that does not allow generalizations, and the particular case does not necessarily represent other cases. The study addresses a company in a specific sector, restricting the possibility of extrapolating the results to other companies, even in the same sector, and to other contexts in which organizations may be inserted. The single case study described an empirical phenomenon in detail but, as part of the intrinsic limitations of the chosen method, suffers from the lack of external validity. Because the intention was to provide insights into peculiar features of the OL process in emergent management challenges, such as the case of AACC, the selfimposed (the lack of) generalizability is the major limitation of the study.

Based on the results and the limitations of this study, future studies can replicate this investigation in different companies and sectors. Also, they can expand the period of time to capture the performance of the adaptation actions. Such a set of results can be used as points of departure in the design of hypothesis to be tested in novel research.

Overall, even though organizations have historically been working toward the adaption to external unforeseen events, anticipatory adaptation to climate change presents new challenges and requires new forms of learning from multiple actors. Regarding theory building, the study of learning for AACC can contribute to the OL literature and knowledge about organizations. Indeed, our study not only contributes to OL literature but also indicates a research gap of extreme relevance in the field of organizations and the natural environment, which should be further studied.

\section{Notes}

1. Regarding the academic literature, "adaptation" carries a caveat worth of a brief note, so as to avoid misunderstandings. The term adaptation to climate change has been used to describe the strategies and activities to cope with observed or expected climatic effects and impacts. The degree of adaptation depends on the adaptive capacity of the system, which plays an important role in reducing its vulnerability (Smit and Pilifosova, 2001). Interestingly, in diverse streams of business literature - strategy in particular - the term "adaptation" has traditionally been used to indicate a reactive attitude toward a specific phenomenon, so to contrast it with proactive behaviors and characteristics of innovative organizations. Paradoxically, in the literature about 


\section{IJCCSM 9,5}

organizations and climate change, "adaption" has been used to describe proactive behaviors. This is because the term adaptation in this context refers to adaptation to future climate-related disruptions, reinforcing the notion that concepts such as "adaptation" and "fit" may pose new and significant challenges when inserted into a climate change perspective (Linnenluecke and Griffiths, 2013). Hence, anticipatory adaptation to climate change (AACC), used in this article, is a more precise term to describe the studies that try to identify how organizations develop anticipatory adaptive capabilities, strategies and processes.

2. National Agency of Electrical Energy, responsible for regulatory issues concerning the Brazilian electricity sector.

\section{References}

Adger, W.N., Arnella, N.W. and Tompkinsa, E.L. (2005), "Successful adaptation to climate change across scales”, Global Environmental Change, Vol. 15 No. 2, pp. 77-86.

Arnell, N.W. (2010), "Adapting to climate change: an evolving research programme”, Climatic Change, Vol. 100 No. 1, pp. 107-111.

Argote, L. and Ingram, P. (2000), "Knowledge transfer: a basis for competitive advantage in firms", Organizational Behavior and Human Decision Processes, Vol. 82 No. 1, pp. 150-169.

Argote, L. and Miron-Spektor, E. (2011), "Organizational learning: from experience to knowledge", Organization Science, Vol. 22 No. 5, pp. 1123-1137.

Armitage, D., Marschke, M. and Plummer, R. (2008), "Adaptive co-management and the paradox of learning”, Global Environmental Change, Vol. 18 No. 1, pp. 86-98.

Argyris, C. and Schon, D. (1978), Organizational Learning, Addison-Wesley, London.

Bajay, S.V. (2006), "Integrating competition and planning: a mixed institutional model of the Brazilian electric power sector", Energy, Vol. 31 No. 6, pp. 865-876.

Baird, J., Plummer, R., Haug, C. and Huitema, D. (2014), "Learning effects of interactive decision-making processes for climate change adaptation", Global Environmental Change, Vol. 27, pp. 51-63.

Berkout, F. (2012), "Adaptation to climate change by organizations”, WIREs Climate Change, Vol. 3 No. 1, pp. 91-106.

Berkout, F., Hertin, J. and Gann, D.M. (2006), "Learning to adapt: organizational adaptation to climate change impacts", WIREs Climate Change, Vol. 78 No. 1, pp. 135-156.

Busch, T. (2011), "Organizational adaptation to disruptions in the natural environment: the case of climate change", Scandinavian Journal of Management, Vol. 27 No. 4, pp. 389-404.

Center for Climate and Energy Solutions (C2ES) (2008), "Adapting to climate change: a business approach", available at: www.c2es.org/docUploads/Business-daptation.pdf

Cyert, R.M. and March, J.G. (1963), A Behavioral Theory of the Firm, Prentice-Hall, Englewood Cliffs, NJ.

Dilling, L. and Lemos, M.C. (2011), "Creating usable science: opportunities and constraints for climate knowledge use and their implications for science policy", Global Environmental Change, Vol. 21 No. 2, pp. 680-689.

Dodgson, M. (1993), “Organizational learning: a review of some literatures”, Organization Studies, Vol. 14 No. 3, pp. 375-394.

Dubey, R., Gunasekaran, A. and Deshpande, A. (2017), "Building a comprehensive framework for sustainable education using case studies", Industrial and Commercial Training, Vol. 49 No. 1, pp. 33-39.

Dyer, W.G. and Wilkins, A.L. (1991), "Better stories, not better constructs, to generate better theory: a rejoinder to Eisenhardt", Academy of Management Review, Vol. 16 No. 3, pp. 613-619.

Eakin, H.C., Lemos, M.C. and Nelson, D.R. (2014), "Differentiating capacities as a means to sustainable climate change adaptation”, Global Environmental Change, Vol. 27 No. 1, pp. 1-8. 
Energias de Portugal (EDP) (2013a), “ClimaGrid: ‘3D’ vision for smart grid”, presentation for Utilities Telecom Council América Latina.

Energias de Portugal (EDP) (2013b), EDP Brasil and INPE Launch Climate Forecast System, the First in the World, for Management of Smart Grids, Press release EDP, Lisbon.

Füssel, H.M. and Klein, R.J. (2006), "Climate change vulnerability assessments: an evolution of conceptual thinking”, Climatic Change, Vol. 75 No. 3, pp. 301-329.

Grothmann, T. and Patt, A. (2005), "Adaptive capacity and human cognition: the process of individual adaptation to climate change", Global Environmental Change, Vol. 15 No. 3, pp. 199-213.

Hallegatte, S. (2009), "Strategies to adapt to an uncertain climate change", Global Environmental Change, Vol. 19 No. 2, pp. 240-247.

Hrebiniak, L.G. and Joyce, W.F. (1985), "Organizational adaptation: strategic choice and environmental determinism”, Administrative Science Quarterly, Vol. 30 No. 3, pp. 336-349.

Huber, G.P. (1991), "Organizational learning: the contributing processes and the literature", Organization Science, Special Issue: Organizational Learning: Papers in Honor of (and by) James G. March, Vol. 2, pp. 88-115.

Intergovernmental Panel on Climate Change (IPCC) (2013), "IPCC WGII AR5 Glossary", www.ipcc.ch/ pdf/assessment-report/ar5/wg2/drafts/fd/WGIIAR5-Glossary_FGD.pdf

Jabbour, C.J.C. and Santos, F.C.A. (2008), "The central role of human resource management in the search for sustainable organizations", The International Journal of Human Resource Management, Vol. 19 No. 12, pp. 2133-2154.

Jabbour, C.J.C., Santos, F.C.A. and Nagano, M.S. (2010), "Contributions of HRM throughout the stages of environmental management: methodological triangulation applied to companies in Brazil", The International Journal of Human Resource Management, Vol. 21 No. 7, pp. 1049-1089.

Jiménez-Jimenez, D., Valle, R.S. and Hernandez-Espallardo, M. (2008), "Fostering innovation: the role of market orientation and organizational learning", European Journal of Innovation Management, Vol. 11 No. 3, pp. 389-412.

Levitt, B. and March, J.G. (1988), "Organizational learning”, Annual Review of Sociology, Vol. 14 No. 1, pp. 319-340.

Linnenluecke, M., Griffiths, A. and Winn, M. (2012), "Extreme weather events and the critical importance of anticipatory adaptation and organizational resilience in responding to impacts", Business Strategy and Environment, Vol. 21 No. 1, pp. 17-32.

Linnenluecke, M.K., Griffiths, A. and Winn, M. (2013), "Firm and industry adaptation to climate change: a review of climate adaptation studies in the business and management field", Wiley Interdisciplinary Reviews: Climate Change, Vol. 4 No. 5, pp. 397-416.

Lucena, A.F.P., Schaeffer, R. and Szklo, A.S. (2010), "Least-cost adaptation options for global climate change impacts on the Brazilian electric power system", Global Environmental Change, Vol. 20 No. 2, pp. 342-350.

Lupp, G., Heuchele, L., Renner, C., Syrbe, R.U., Konold, W. and Siegrist, D. (2016), "Motivations and attitudes to (not) take action for climate change adaptation in protected areas", International Journal of Climate Change Strategies and Management, Vol. 8 No. 3.

Marx, S.M., Weber, E.U., Orlove, B.S., Leiserowitz, A., Krantz, D.H., Roncoli, C. and Phillips, J. (2007), "Communication and mental processes: experiential and analytic processing of uncertain climate information", Global Environmental Change, Vol. 17 No. 1, pp. 47-58.

Morton, T.A., Rabinovich, A., Marshall, D. and Bretschneider, P. (2011), "The future that may (or may not) come: how framing changes responses to uncertainty in climate change communications", Global Environmental Change, Vol. 21 No. 1, pp. 103-109.

Moss, R.H. (2007), "Improving information for managing an uncertain future climate", Global Environmental Change, Vol. 17 No. 1, pp. 4-7. 


\section{IJCCSM 9,5}

National Institute for Space Research (INPE) (2010), INPE and EDP Launch Project for the Electricity Sector to Face Climate Change, Press Release, www.inpe.br/webelat/homepage/menu/noticias/ release.php?id $=4$ (accessed 30 November 2010)

National Institute for Space Research (INPE) (2014), História, www.inpe.br/institucional/sobre_inpe/ historia.php\#

Nevis, E.C., DiBella, A.J. and Goud, J.M. (1995), "Understanding organizations as learning systems", Sloan Management Review, Vol. 36 No. 2, pp. 73-85.

Owens, S. (2010), "Learning across levels of governance: expert advice and the adoption of carbon dioxide emissions reduction targets in the UK", Global Environmental Change, Vol. 20 No. 3, pp. 394-401.

Pesonen, H.L. and Horn, S. (2014), "Evaluating the climate SWOT as a tool for defining climate strategies for business", Journal of Cleaner Production, Vol. 64, pp. 562-571.

Pereira, A.O., Jr., Costa, R.C., Costa, C.V., Marreco, J.M. and Rovere, E.L. (2013), "Perspectives for the expansion of new renewable energy sources in Brazil", Renewable and Sustainable Energy Reviews, Vol. 23, pp. 49-59.

Pérez López, S., Manuel Montes Peón, J. and José Vazquez Ordás, C. (2005), "Organizational learning as a determining factor in business performance", The Learning Organization, Vol. 12 No. 3, pp. 227-245.

Ruona, W.E.A. (2005), "Analyzing Qualitative Data”, in Swanson, R.A., Holton, E.F. III, Research in Organizations: Foundations and Methods of Inquiry, Berrett-Koehler, San Francisco, CA.

Sánchez, J.A.L., Vijande, M.L.S. and Gutiérrez, J.A.T. (2010), "Organisational learning and value creation in business markets”, European Journal of Marketing, Vol. 44 Nos 11/12, pp. 1612-1641.

Siggelkow, N. (2007), "Persuasion with case studies", The Academy of Management Journal, Vol. 50 No. 1, pp. 20-24.

Smit, B. and Pilifosova, O. (2001), "Adaptation to Climate Change in the Context of Sustainable Development and Equity", Chapter 18, IPCC. Climate Change 2001: Impacts, Adaptation, and Vulnerability - Contribution of Working Group II to the Third Assessment Report of the Intergovernmental Panel on Climate Change, Cambridge University Press, Cambridge, pp. 877-912.

Stake, R.E. (1998), "Qualitative Case Studies", in Denzin, N.K. and Lincoln, Y.S. (Eds), The Sage Handbook of Qualitative Research, Sage, London.

Storbjörk, S. (2010), "It takes more to get a ship to change course: barriers for organizational learning and local climate adaptation in Sweden", Journal of Environmental Policy \& Planning, Vol. 12, pp. 235-254.

Sustainability Center of Getúlio Vargas Foundation (GVces) (2013), "Forum debates the role of private sector on the implementation of adaptation actions to climate change in Latin America", available at: www.gvces.com.br/index.php?r=site/conteudo\&id=495

Tankha, S. (2008), "From market to plan: lessons from Brazilian power reforms on reducing risks in the provision of public services", Policy and Society, Vol. 27 No. 2, pp. 151-162.

Templeton, G.F., Lewis, B.R. and Snyder, C.A. (2002), "Development of a measure for the organizational learning construct", Journal of Management Information Systems, Vol. 19 No. 2, pp. 175-218.

Tippins, M.J. and Sohi, R.S. (2003), "It competency and firm performance: is organizational learning a missing link?”, Strategic Management Journal, Vol. 24 No. 8, pp. 745-761.

Vogel, C., Moser, S.C., Kasperson, R.E. and Dabelko, G.D. (2007), "Linking vulnerability, adaptation, and resilience science to practice: pathways, players, and partnerships", Global Environmental Change, Vol. 17 Nos 3/4, pp. 349-364.

Voss, C., Tsikriktsis, N. and Frohlich, M. (2002), "Case research in operations management", International Journal of Operations \& Production Management, Vol. 22 No. 2, pp. 195-219.

Ziervogel, G., Cartwright, A., Tas, A., Adejuwon, J., Zermoglio, F., Shale, M. and Smith, B. (2008), Climate Change and Adaptation in African Agriculture, Stockholm Environment Institute, available at: www.environmentportal.in/files/5_22.pdf 


\begin{tabular}{lll}
\hline Constructs & Examined aspects & Related questions \\
\hline
\end{tabular}

Knowledge acquisition

Learning from experiences

Observation of other organizations

Grafting components that possess needed knowledge Searching for information about environment and performance

Information distribution

Distributing information through the organization

Information interpretation

Organizational memory

\section{Giving meaning for} information, translating events and developing shared understandings and conceptual schemes Storing what has been learned in memory and then brought forth from memory
Which learning related to ClimaGrid resulted from systematic efforts (programmed) and resulted from not systematized efforts (unscheduled)? Were there some modifications in the project that had not been planned?

In addition to changes in routines and tasks (single loop), has ClimaGrid generated changes or questions about the values, behavior and organizational goals (double loop)? What changes in the process of adaptation to extreme weather events can be attributed to ClimaGrid? It is possible to establish a cause - effect relationship between the ClimaGrid and the results generated for business? How can this be accessed?

What external partnerships were made for the development of ClimaGrid? How were these partnerships established? Does the company hold or held benchmarking with other organizations or tools to develop and refine the ClimaGrid? Does the company have external channels for obtaining knowledge related to adaptation, such as consultants, experts, meetings with professionals, etc.?

Has the company hired new staff with specific expertise for the development and operation of ClimaGrid?

Which internal and external barriers hindered the implementation of ClimaGrid?

What were the main results generated by ClimaGrid? How is its effectiveness evaluated?

Is there a performance monitoring tool?

How are data collected via ClimaGrid accessed?

How different areas access the ClimaGrid Information? Do all areas have access to the data?

How data collected via ClimaGrid was interpreted?

How does ClimaGrid transform data collected into information for decision making?

Do different employees/areas tend to interpret them in different ways?

How is historical information stored? How is it used?

Do different areas/employees know about the existence of the information generated by the tool and where they are stored? How is the turnover of employees operating ClimaGrid? Are the methods and standards for using ClimaGrid documented and stored for future users?
Table AI.

Questions related to

OL constructs

\section{Corresponding author}

Simone R. Barakat can be contacted at: simonebarakat@usp.br

For instructions on how to order reprints of this article, please visit our website:

www.emeraldgrouppublishing.com/licensing/reprints.htm

Or contact us for further details: permissions@emeraldinsight.com 